\title{
The Use of Accurate Pore Pressure Monitoring for Risk Reduction in Tailings Dams
}

\author{
Kym Lesley Morton ${ }^{1}$ (D)
}

Received: 19 February 2020 / Accepted: 29 October 2020 / Published online: 6 January 2021

○) Springer-Verlag GmbH Germany, part of Springer Nature 2021

\begin{abstract}
Simply monitoring movement of the tailings dam wall does not address the cause of tailings dam failures and will therefore never be an effective method to reduce or prevent failures. Monitoring the causes of failures is more effective. The main cause of tailings dam failure is slope instability, which is caused by too much water in the wrong place. Accurate pore pressure monitoring of the pressure (weight) of water in the tailings storage facility (TSF) slopes and plotting of flow lines beneath and upstream of the TSF can guide and enable early intervention to prevent or delay failure. Remote monitoring linked to artificial intelligence and robotics to turn on pumps and open drains to address and remove the cause of failure can help reduce risk. Installation of multiple point piezometers in an accurate pattern allows the plotting of equipotentials and flow lines in three dimensions. Each TSF is unique and requires its own monitoring design, which should be tailored to match the age, structure, and specific causes of risk. Once understood, the monitoring system can be coupled to a reporting system to significantly reduce the risk of failure at both legacy and active sites.
\end{abstract}

Keywords Piezometers $\cdot$ TSF $\cdot$ Robotics $\cdot$ Artificial intelligence $\cdot$ Equipotentials $\cdot$ Satellite tracking

\section{Introduction}

The main cause of failure is slope instability (Cenderelli 2000). The presence of water within and beneath the TSF reduces the stability of the face (the slope of the dam wall) by modifying the shear stresses on the potential failure surfaces. Once the slope of a tailings storage facility (TSF) has been established, either during the building of an early section or completion of a final lift, the only significant factors that can be controlled to reduce the risk of failure are the weight of water in the slope of the faces and the upward pressure of groundwater.

Water pressure is measured by recording pore pressures within the dam wall and beneath the TSF. This paper describes the distribution of pore pressures within a TSF face and gives a recommended methodology for measurement and control of pore pressures in the faces at risk of failure and the areas below and above the TSF that contribute to its water regime. Modern techniques for tailings dam

Kym Lesley Morton

kmorton@klmcs.co.za

1 KLM Consulting Services Pty Ltd (KLMCS), PO Box 119, Lanseria 1748, South Africa monitoring emphasise the measurement of slope movement using radar, lidar, and prisms. However, these techniques only measure the reaction of slopes to instability factors and do not address the causes of failure or reduce the risk. Addressing the cause of failure is essential to managing the risk and preventing or reducing failure. Modern big data management techniques, artificial intelligence (AI), and robotics controlled via local or remote monitoring using satellite links can be used to increase control and reduce risk. Integration of geotechnical design, accurate monitoring, and engineering can substantially improve management and reduce risk. The efficiency of remote monitoring has increased during the Covid-19 reduction in human interaction; robotics and satellite controls offer the opportunity to continue this improvement. The recent publication of the global standards on tailings (Oberle 2020) describes 15 principles; accurate monitoring of causation plus transparency in reporting addresses Principles $2-10$ and supports Principles 12 and 15. Understanding the opportunities to improve monitoring design and reporting objectives requires a basic understanding of the anatomy of a TSF. This paper describes typical construction, monitoring techniques, network design, and the opportunities for remote sharing of information to reduce risk. 


\section{Typical TSF Construction}

The main types of TSFs are classified by either the method of construction or purpose: 1 . upstream; 2 . downstream; 3. centreline; and 4. water retention. Figure 1 shows the upstream, downstream, and centreline methods of construction. These use a combination of the tailings material and other materials for construction. Figure 2 shows the intermediate or final construction of a centreline TSF with a large pond.

Most old tailings dams were constructed by piling material into depressions in the ground or riverbeds and therefore have weak foundations and no lining and are thus hydraulically connected with underlying aquifers. The TSFs located on riverbeds can have an underlying instability and it is very important that the water pressure beneath and upstream of the TSF be monitored, though each TSF is unique and has its own characteristics. Older TSFs may have had several phases of construction and therefore need a carefully designed monitoring network that measures each causative factor that increases risk of failure.

Few TSFs are established on a flat plain (as usually depicted in textbooks). Figure 3 shows examples of TSFs established on mountainous terrain.

Although every TSF is different and requires its own monitoring design, they all hold water, in a pond and/or held in sediments; both require accurate monitoring to reduce the risk of failure. For accurate control, saturated sediments

\section{Types of sequentially raised tailings dams}

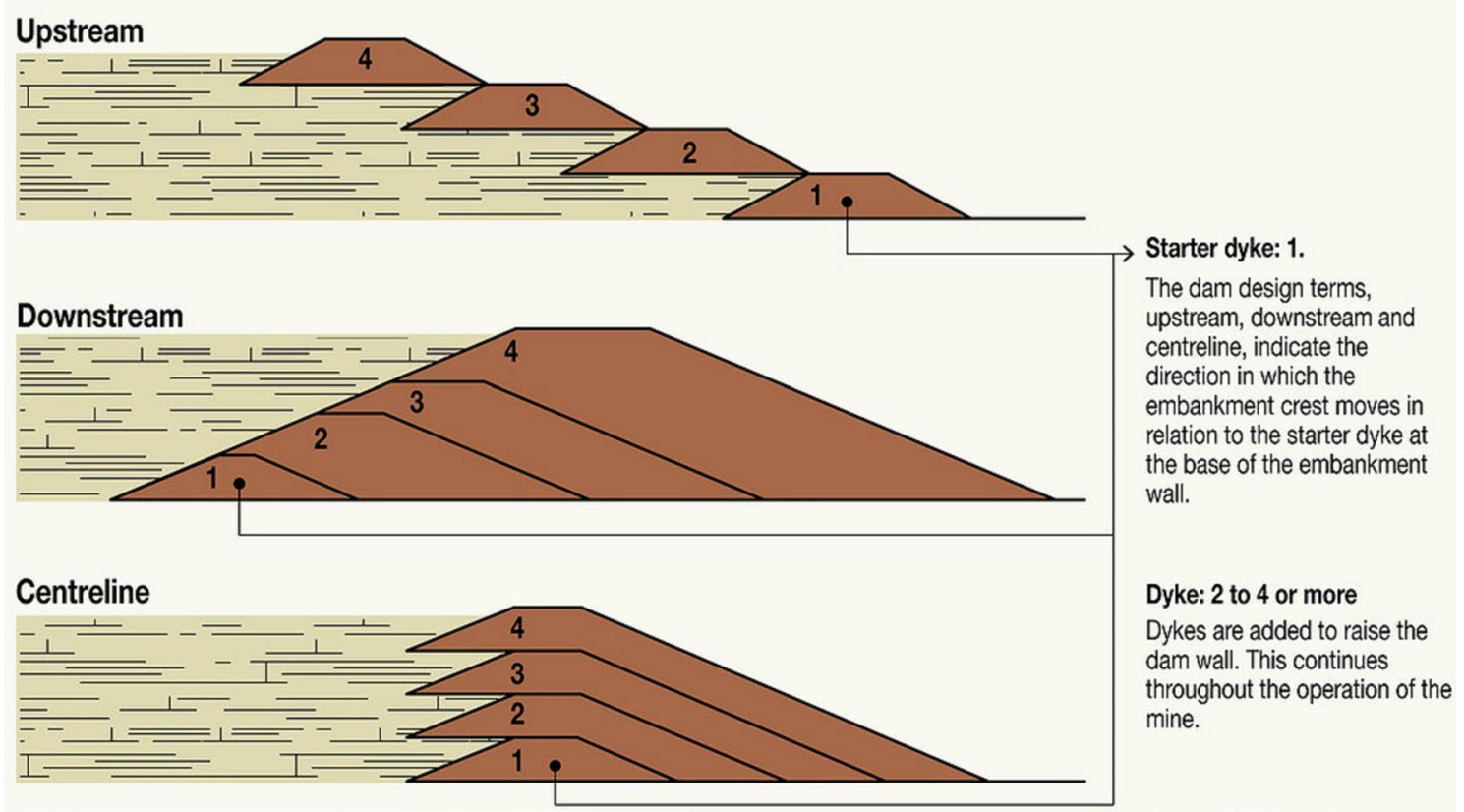

Fig. 1 Types of sequentially raised tailings dams or TSF (Vick 1983, 1990)

Fig. 2 Final construction of a tailings dam or TSF

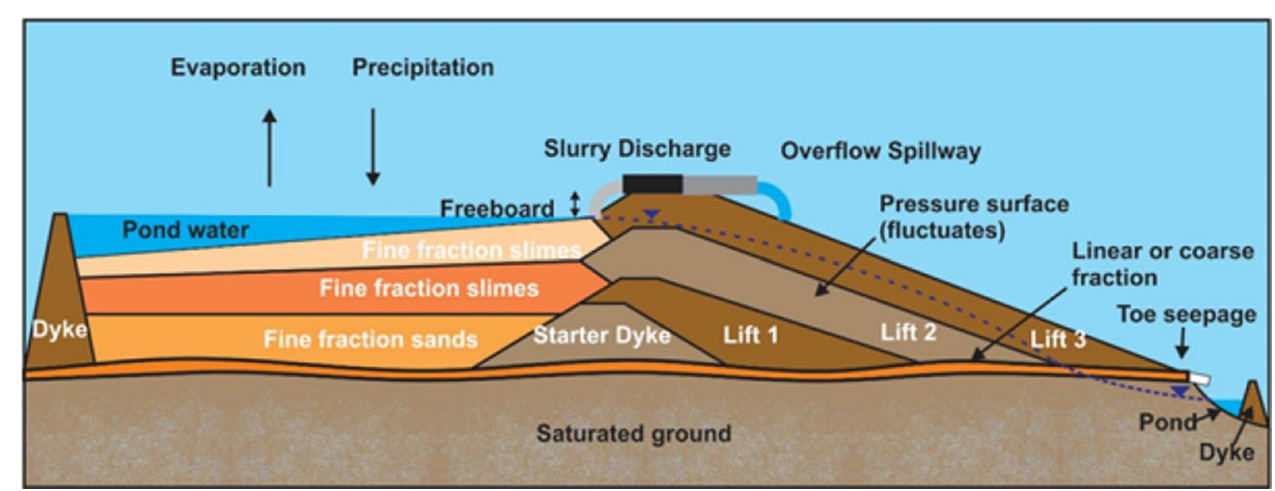



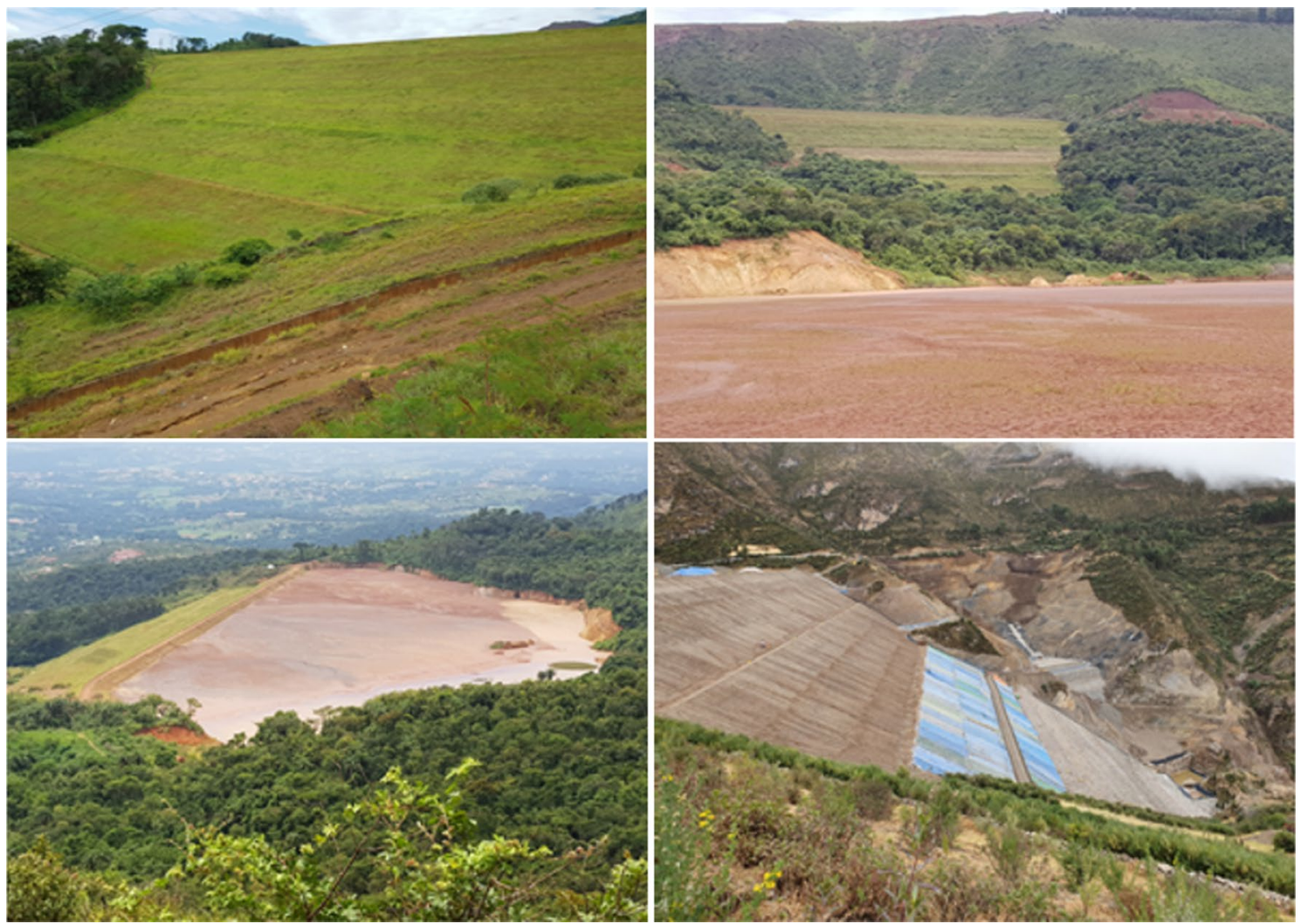

Fig. 3 Examples of TSFs established on mountainous terrain (Courtesy: A. Copeland)

require measurement of the distribution and changes in pore pressure and effective stress.

\section{Pore Pressures and Effective Stress}

Pore pressure monitoring is essential because failure, known as volume deformation, in a slope will present (under various pressures and stresses) as three possible scenaria:

1. Compression of water in the pores of the material.

2. Compression of individual particles (sediments etc.)

3. Rearrangement of particles, usually to a more compact configuration.

As described in an earlier paper (Morton et al 2008), the stress state for any point in a slope is governed by the principal stresses and the acting water pressure (measured as pore pressure). Figure 4 shows the directions of stress acting on a hypothetical plane within a saturated medium.

The primary effect of groundwater pressures is through effective stress. Rearrangement of particles (slope failure) is caused by changes in effective stress. The stress state at any given point and any time is governed by the principal stresses and acting pore pressure. The Mohr-Coulomb

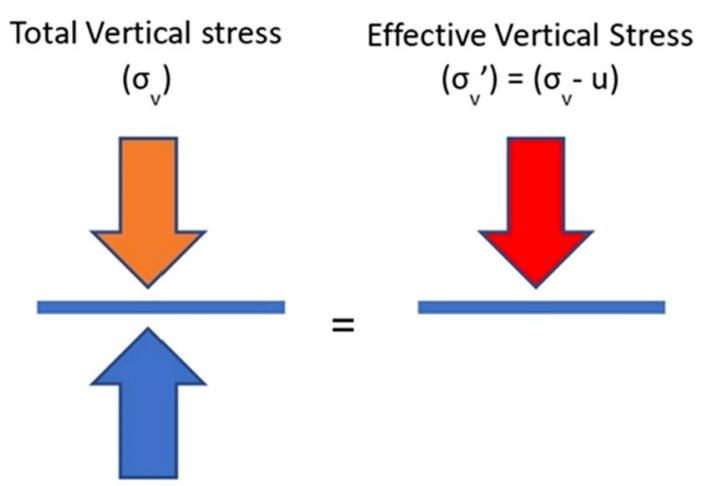

Fluid pressure

(u)

Morton et al 2008

equation (Eq. 1), derived from the Coulomb-Terzaghi equation, states:

$\tau=c+(\sigma-p) \tan \varnothing$

where: $\tau=$ shear strength; $\sigma=$ total normal stress; $p=$ pore water pressure; $\varnothing=$ internal angle of friction; and $c=$ cohesion. The strength, and therefore stability of the slope, is 
created by the cohesion and weight of the materials making up the slope. Weakness comes from excessive pore water pressures and the internal angle of friction. Any reduction in the effective stress $\left(\sigma^{\prime}=\sigma-p\right)$ will reduce the shear strength of the slope material. Therefore, in stability analysis, it is essential to know the distribution of pore pressures within the slopes of a TSF and beneath or upstream of a TSF. Once pore pressures are plotted, the pressure gradient within a homogenous slope will look like Fig. 5.

This figure shows that the flow lines are orthogonal to the equipotentials plotted from the pressure readings. This flow line information can be used to model the stability of the slope and establish the location of the optimum phreatic surface for the dam wall. This information can then be used to improve safety and reduce risk. For non-homogenous materials, the pattern will be more complex; however, with accurately placed and well-distributed point piezometers, the equipotentials can be plotted.

\section{Measurement of Pore Pressures}

Pore pressures can be measured in three dimensions (four if you include time), using pressure transducers. These are often of the sealed vibrating wire point type and installed at specific points in a slope or dam wall. These point piezometers are grouted into boreholes drilled into critical sections of the slopes of the tailings dam retaining walls. The best placement of the point piezometers for critical areas of the TSF can be established using flow net plotting or numerical modelling based on what is known or assumed about the construction of the dam walls and underlying groundwater movement. Figure 6 shows a typical pressure transducer of the vibrating wire piezometer type.

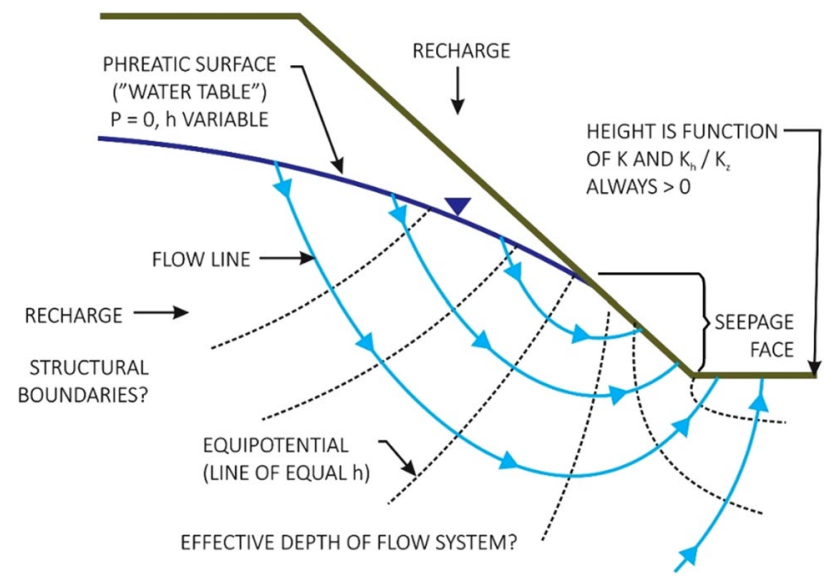

Fig. 5 Anatomy of the pressure gradients within a slope of a tailings dam (TSF)

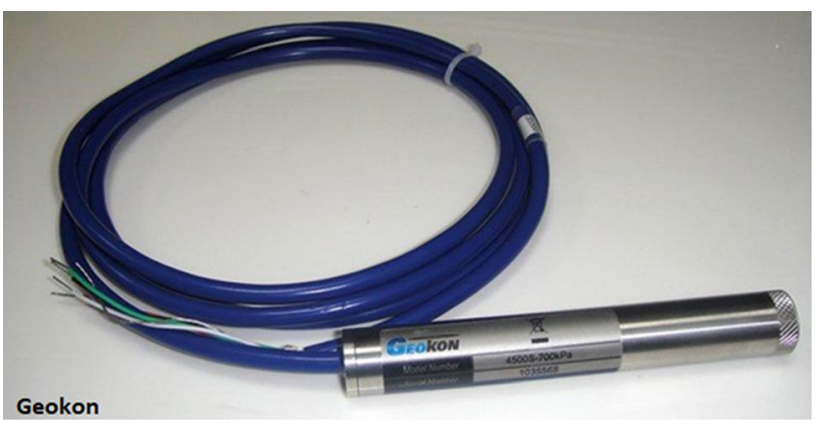

Fig. 6 Example of a vibrating wire piezometer prior to insertion

Plotting three-dimensional distribution of pore pressures requires installation of nested piezometers, typically three piezometers sealed at designed intervals in each drill hole. The location and construction of the nested piezometers depends on the construction and dimensions of the slopes, but often three rows of three nested piezometers can be used in most TSF's. Upstream and downstream installations can be used to monitor upstream and downstream pressure distributions.

The borehole diameter for piezometer installation depends on the type of piezometer installation being constructed. The drilled diameter needs to be large enough to accommodate the gravel pack, the seal, and the diameter of the tremie pipe used to deliver the sealant (grout) to the correct location during installation.

The head measurement represents the vertical hydraulic head at the measuring point. The cables transmitting the pressure readings are connected at the surface to a data logger or sim card so measurements can be sent in real time to a central data monitoring device (Fig. 7). This data can then be converted into information such as trend graphs and used to create knowledge for TSF management.

Nested grouted-in piezometers can be used in vertical boreholes to monitor water pressures around and beneath the

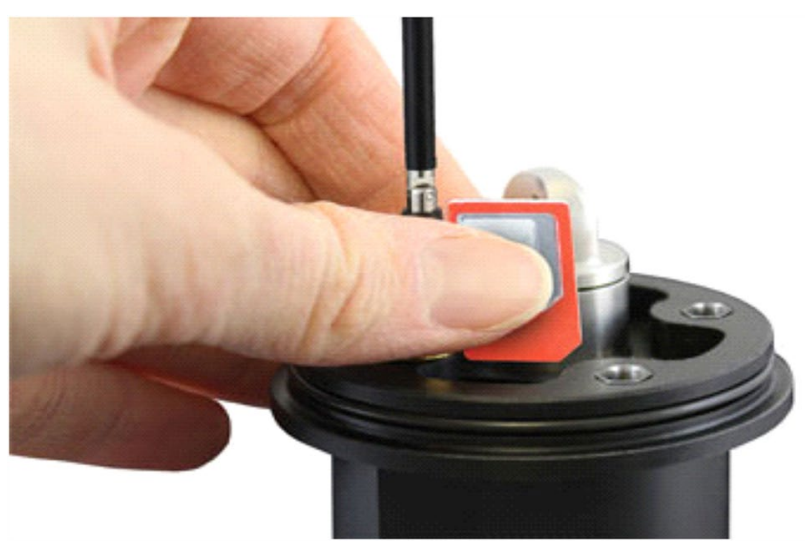

Fig. 7 Wireless transmitter sim card installation 
Fig. 8 Nested grouted-in pressure transducers $\mathbf{a}$ in one borehole and $\mathbf{b}$ in a cluster of boreholes (Morton 2020)

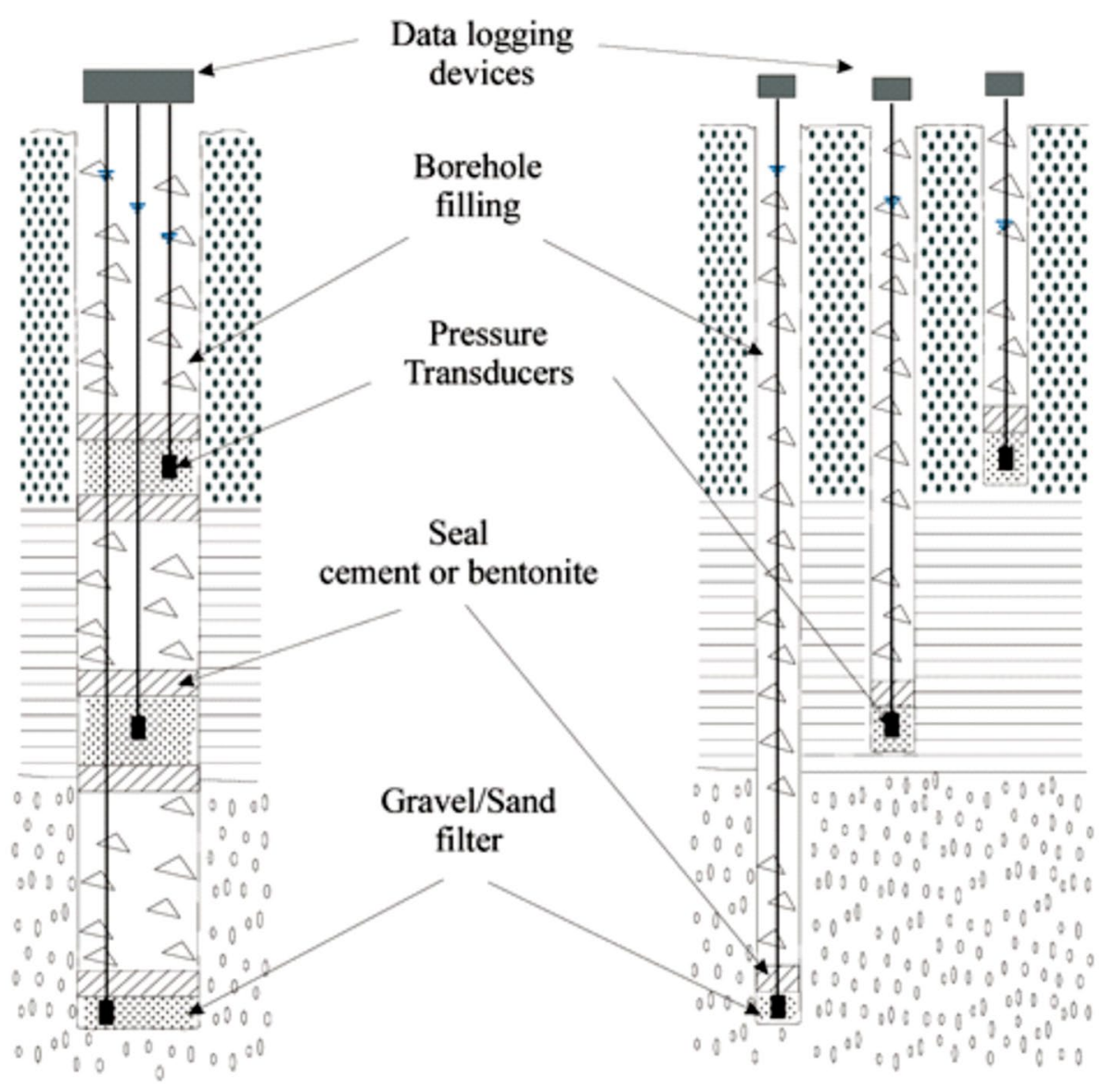

(a)
TSF. Figure 8 shows installations using either one borehole or three.

Piezometers can also be installed in angled holes, preferably sub-horizontal, when installed from the face of the monitored slope. Figure 9 shows the construction of an angled point piezometer installation in the face of a TSF.

The same construction design is used for nested piezometers installed at multiple locations in a TSF face and
Fig. 9 Installation of an angled piezometer (Read and Stacey 2009)

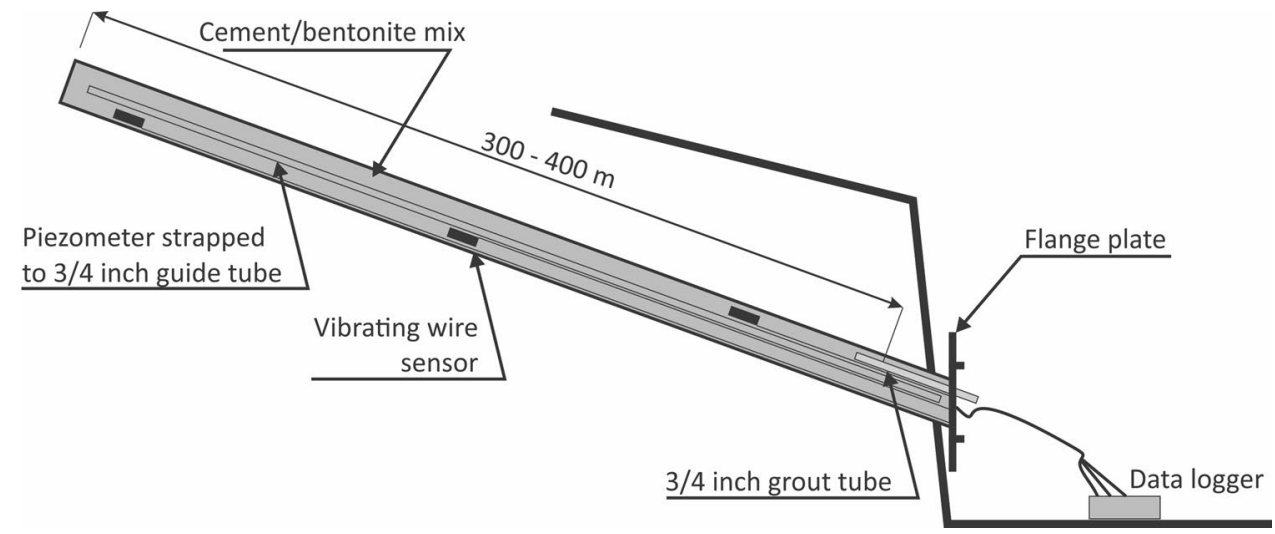

below the foundations. Figure 10 illustrates a possible layout of multiple sub-horizontal nested piezometers in a TSF that was built in a steep valley. 


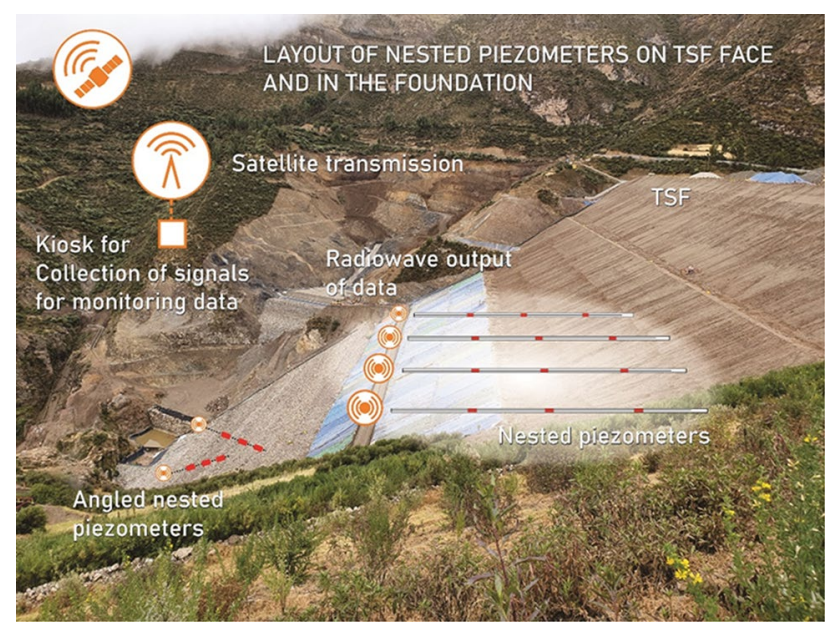

Fig. 10 Nested piezometers installed in a TSF face and foundation

\section{Design of a Monitoring Network}

Monitoring network design depends on the age, shape, and construction of the TSF, as well as its location within the overall catchment that contributes to its water balance. A TSF cannot be monitored accurately without monitoring the effect of the catchment it occupies since the water balance of a TSF is affected by rainfall input to its pond and on surface runoff upstream. The groundwater levels around, below, and upstream affect the water balance of the TSF, and these too need to be monitored and managed to reduce upward pressure and increase safety.
Figure 11 shows the typical movement of groundwater flow below a TSF located in a valley. Even TSFs located on flat terrain can have upward pressure from groundwater, depending on the local geology and depth of weathered material below the TSF.

Accurate monitoring depends on understanding all of the water pressures that act on a TSF. Using a conceptual model like Fig. 11 enables an initial assessment of the flow lines and pressures that should be measured to give a good indication of where to install point piezometers. More advanced analysis can be done using more detailed geological crosssections, geological structures, numerical modelling, sensitivity analysis, and calibrated using existing groundwater level records from open boreholes. Figure 12 shows the layout of an accurate monitoring network around an individual tailings dam (in plan view).

At this site, rainfall, evaporation, pond water levels, downstream pond water levels, overflow, point piezometers in the slopes, regional groundwater level, and movement are all monitored. All information is collected in real time and transmitted via satellite to multiple dashboards designed for multiple users. Cloud storage is possible, as is on-site storage or the use of smart phones for on-site audits. The details can be used by geotechnical engineers to support their designs and set safety targets. Engineers on site can use the water levels and pressure monitoring to control water levels and pressures.

The advantage of this system is that the design can be modified for each unique TSF. The monitoring results can be linked to interpret trends and used to warn of water pressure build-up, which can cause failure. Once a trend in water pressure build-up is noticed or a target level is breached, then

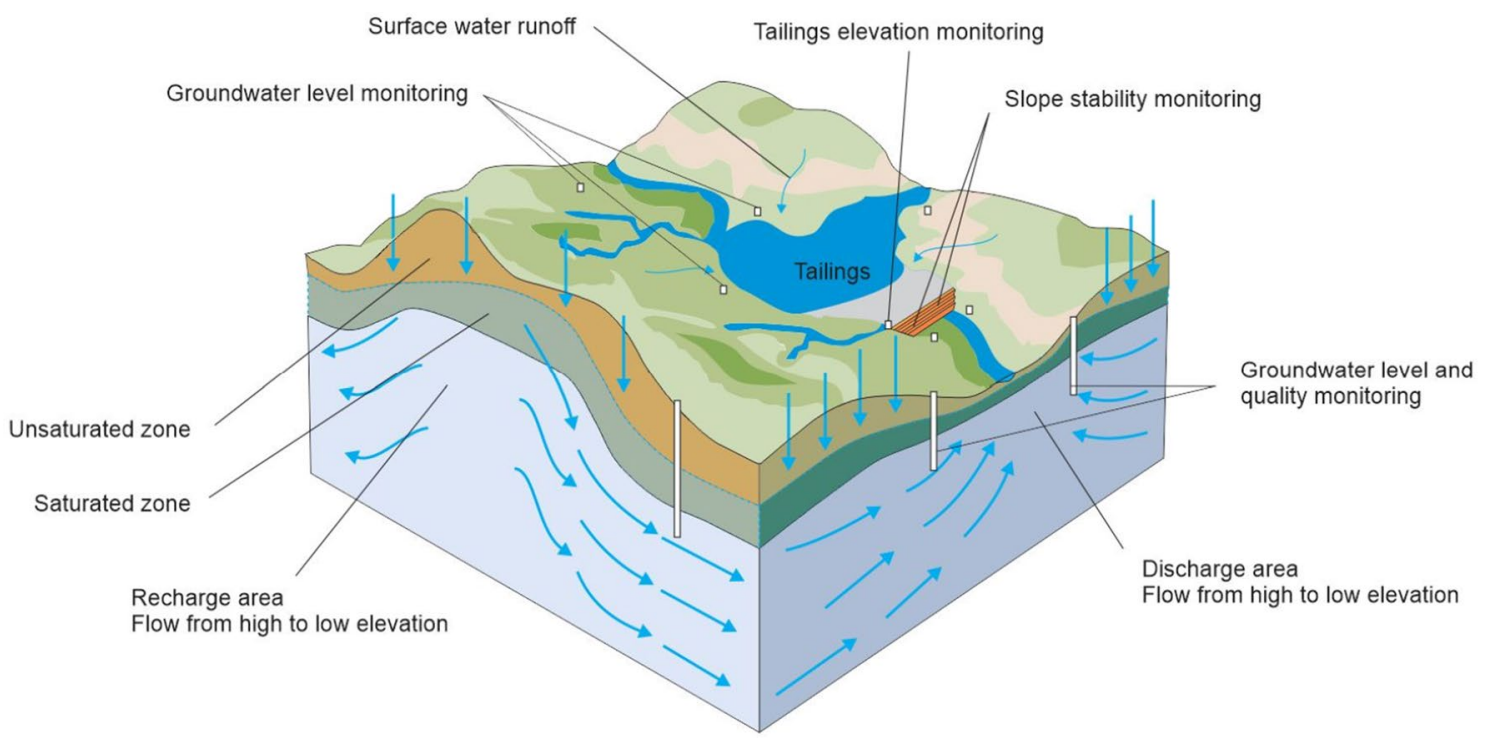

Fig. 11 The schematic diagram for a tailings dam with safety monitoring 


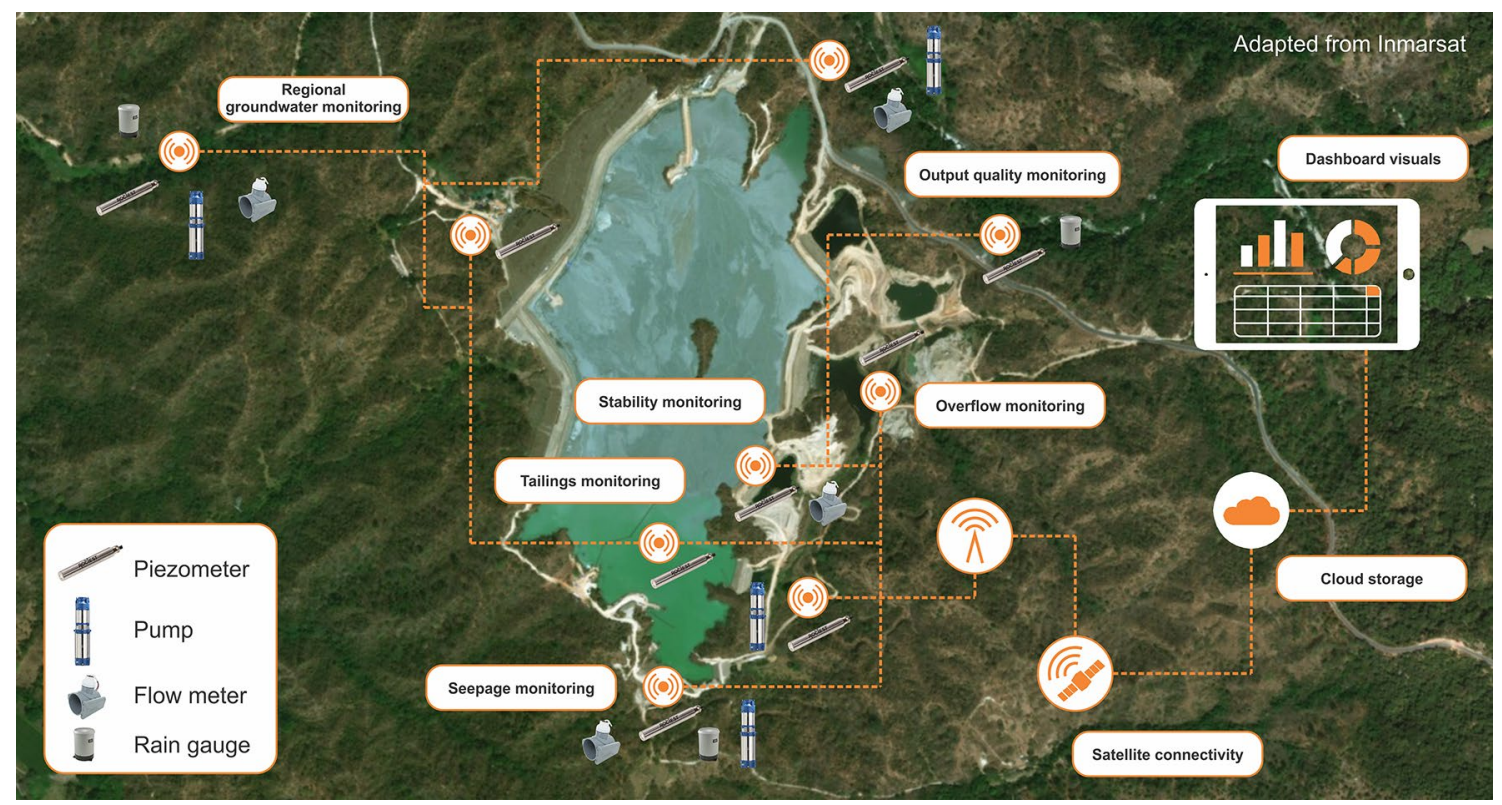

Fig. 12 Location of monitoring points for a typical valley TSF

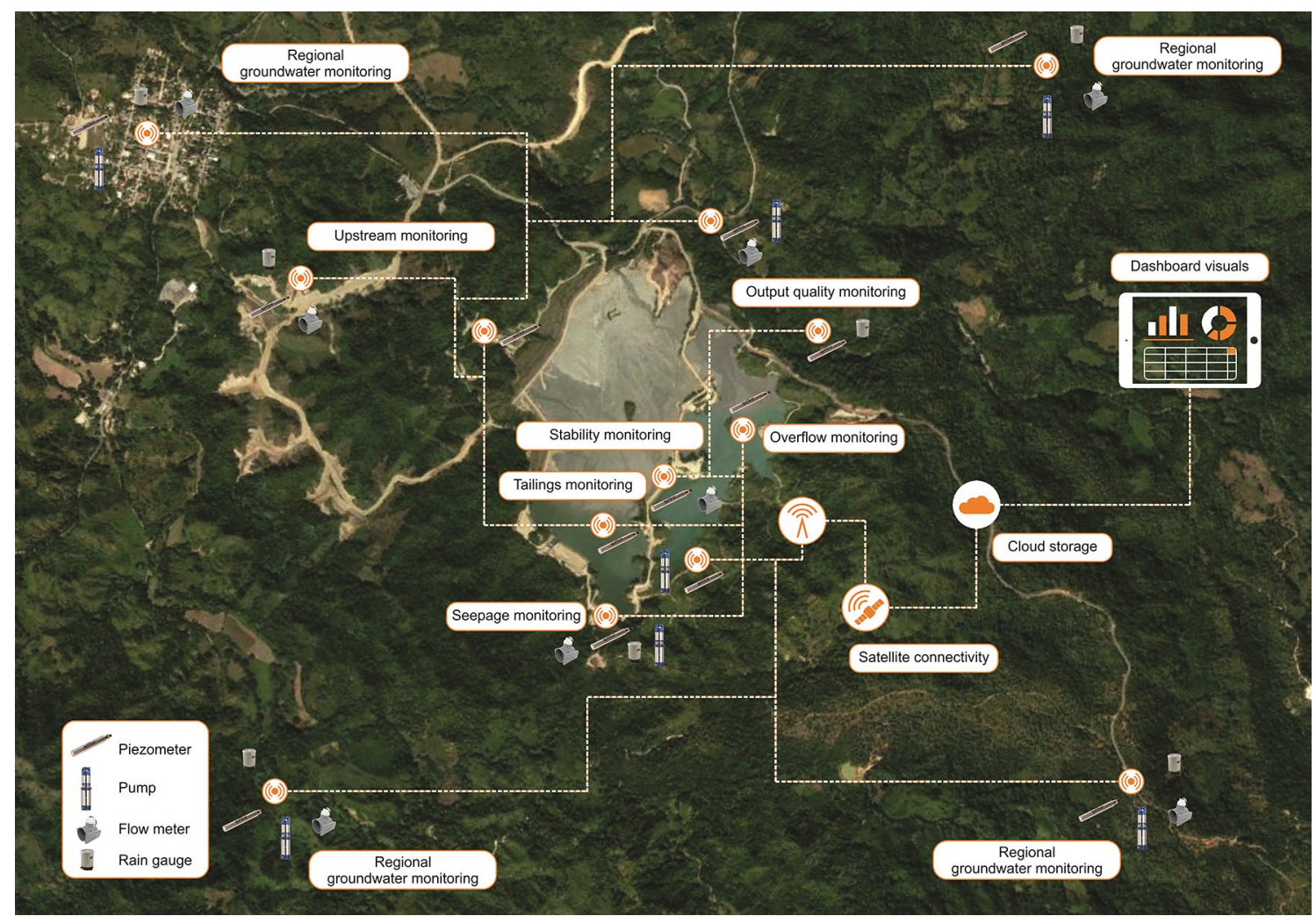

Fig. 13 Example of layout for a TSF's entire catchment

mitigation measures using a TARP (trigger action response programme) can be immediately applied to prevent or delay failure. Actions include increasing pumping from boreholes or activating more drain holes. Barry (2020) states that "AI 
and robotics have the ability to both enhance resilience and manage and act upon data more efficiently than humans". Many software companies are working on the platforms and linkages to ensure seamless connectivity. Sharing and visualisations of systems can enhance transparency and understanding of TSF management with all stakeholders.

The initiatives fit well with the new global guidelines on tailings standards published in August 2020 (Oberle 2020) and are a firm move to transparency in tailings management. The transparency will benefit all stakeholders and improve the insurability of TSFs.

A regional monitoring network is recommended for accurate prediction and management of a TSF's water balance and movement. Figure 13 is the same area as Fig. 12 but expanded to include monitoring stations throughout the catchment. This is particularly important in semi-arid environments, which often have rainfall events high up in the catchment that then raise ground- and surface-water levels and create flooding lower down in the catchment, with adverse impacts on a TSF.

\section{Conclusions}

All TSFs are unique and require a unique monitoring network that addresses the cause of failure and not just the the movement of slopes. The main cause of failure is an increase in water pressure in the slopes of the TSF or beneath the TSF. This can be measured by the judicious placement of point piezometers in critical areas of the slopes. Pore pressure data can be used to understand and predict instability, thereby enabling corrective action and risk reduction. This information can be incorporated in the geotechnical design packages to set maximum water level or pressure limits. Modern remote data sharing techniques can then be used to enable observation and visualisation in real time, thus encouraging transparency in tailings management.

Acknowledgements We thank the reviewers and input from Simon Barry of the Advisory Group, Cape Town.

\section{References}

Barry S (2020) The risk based approach to water, tailings, ESG and major challenges in the mining industry - the economics and ethics. The Advisory Group, Mining Review, July 2020

Cenderelli DA (2000) Floods from natural and artificial dam failures. In: Wohl EE (ed) Inland flood hazards: human, riparian, and aquatic communities. Cambridge University Press, New York, pp 73-103

Morton KL (2020) Tailings dam risk reduction using accurate pore pressure monitoring. Proc, South African Institute of Mining and Metallurgy Tailings Storage Conf, https://firstafricaguid e.com/2020/02/06/tailings-dam-risk-reduction-using-accuratepore-pressure-monitoring/. Accessed 6 Feb 2020

Morton KL, Muresan MC, Ramsden F (2008) Importance of pore pressure monitoring in high walls. J S Afr Inst Min Metall 108(11):661-667

Oberle B (2020) Global industry standard on tailings management. www.globaltailingsreview.org. Accessed 6 Feb 2020

Read J, Stacey P (2009) Guidelines for open pit slope design. CSIRO, Collingwood

Vick S (1983) Planning, design, and analysis of tailings dams. Wiley, New Jersey

Vick S (1990) Planning, design, and analysis of tailings dams. Wiley, New Jersey 